\title{
Effects of preservative on foetus tissues and DNA profiling in forensic cases
}

\begin{abstract}
Sexual assault with female minor children is a major problem in the developing countries. The poor education level of victim and perpetrator is one of the reasons for sexual assault. Victims of age 13 to 17 years are more prone to get pregnant and they discover the pregnancy in the stage of 4 weeks to 10 weeks. Pregnancy terminated and foetus preserved for DNA profiling to ascertaining the paternity to convict the accused on the basis of DNA profiling report. The foetus preservation is done by the gynaecologist and it is preserved in the formalin or in the normal saline. Foetus and placenta are preserved in two preservatives either in formalin or normal saline. In this study we have taken the three types of samples from foetus one is toe, limb (leg) in normal saline and rest upper major part of the foetus in formalin. This study concludes that better DNA quality, quantity and DNA profiles were obtained from the toe samples preserved in normal saline comparative to any other tissues preserved in formalin.
\end{abstract}

Volume 3 Issue 4 - 2018

\author{
Naresh Kumar,' Aanchal Maitray,' Ritika \\ Gupta,' Shukla SK ${ }^{2}$ \\ 'Forensic Science Laboratory, India \\ ${ }^{2}$ Director and Head of Amity Institute of Forensic Science, \\ Amity University, India
} Correspondence: Naresh Kumar, Forensic Science Laboratory,
Home Department, GNCT OF Delhi, Rohini, Delhi, India,

Email nareshkumar2982@yahoo.com

Received: May 29, 2018 | Published: July 02, 2018

Keywords: sexual assault, preservation, formalin, DNA quantity, PCR inhibitors

\section{Introduction}

It was in the news when a 10 year old girl became pregnant at Chandigarh in India after being repeatedly raped by a relative in 2017. There are lots of cases of teenage pregnancies involving 14 to 17 year olds. The girl in question has been described as a happy smiley child. On 28 July, Supreme Court of India rejected a petition filed on her behalf to allow her to abort, on the grounds that it is 32 weeks pregnancy. A doctors' panel was formed and advised the court that a termination at this stage would be too risky for the girl, and foetus was doing well. It was a huge disappointment for the girl's family. In another case a girl eloped with some friend on 6 September at 7 AM in the morning when she went to the school and did not turn back. First Information report was registered in the nearby police station. The girl was recovered on 31 March and medical examination was done and she was declared pregnant. MTP was done on the 12 May. Total five items were collected including part of foetus in the form of tissue in normal Saline (NS), complete foetus in formalin and placenta in two parts in formalin as well as normal saline, along with blood sample of the victim.

Cases of pregnancy in minor girls are common due to less knowledge about consequences of sexual act and victim gets pregnant. When they came to know about the pregnancy it becomes too late. Minor victim do not disclose the pregnancy to the family members due to hesitation, poor education or not aware about the sexual activity. Advancement in DNA analysis, methodology has improved a lot for determination of paternity of the foetus in such cases. The DNA technology helps the victim to get the DNA profile of the foetus and conclude the paternity of the child and convict the accused on the basis of scientific evidence. The foetus preservation and DNA profiling from the samples is an issue to the forensic scientist. The Real time PCR technology has enabled forensic scientists to analyse the samples with sufficient quantity of DNA and profiling thereof. This technique helps in qualitative, quantitative analysis of DNA. Preservative like formalin affects the sample and also marks the presence of inhibitors in the samples. ${ }^{1}$ Formaldehyde the component of formalin leads to generation of cross linking between DNA and protein and causes DNA to fragments. The ethanol can be used for removing the formalin.
The removal of formalin and quantity of DNA can be checked by the use of Real Time PCR. The quantitation of forensic sample is an important part of DNA analysis as it may tell how much DNA is there and how much we have to use for conventional PCR. Proper amount of amplicons concentration is required for complete DNA profiling, otherwise split peaks, and off ladder alleles will be seen in the profile. ${ }^{2}$ Inhibitors in the sample may directly bind to DNA or interact with DNA polymerases (eg. Tag polymerase). They are sensitive to various inhibitors and thus, amplification process is obliterated. ${ }^{3}$ The best way to avoid PCR inhibition is by preventing inhibitors from being processed along with the samples. Direct use of degraded or formalin used samples may affect the autosomal STR analysis resulting in unsuccessful or partial DNA profile and may cause false-negative results. ${ }^{4}$ The DNA technology is the robust and powerful tool in the prevailing technology standards for criminal justice systems. ${ }^{5}$ The microsatellites used for human DNA profiling has 4 to 5 nucleotides repeats. The quantity and quality of extracted DNA affects the success of its analysis and the overall quality of the final DNA profiling. Amplification and suboptimal input amount of alleles leading to imbalance in size of heterozygous peak heights and further allelic drop of large sized markers. The failure to remove inhibitors during the extraction process may result in poor amplification of certain big sized marker or the failure to generate the full and accurate DNA profile or generate false-negative results.

\section{Materials and methods}

Aborted foetus/tissue are preserved by the gynaecologist in the preservative either in formalin and normal saline and sent to the laboratory and preserved at -20 degree Celsius temperature to diminish degradation of the sample. The tissue material of equal quantity from each sample was taken for washing and it was washed with Milli Q water or use of alcohol to avoid any contamination and removal of formalin. Each day three to four washing were given to the each sample but in case formalin mixed tissue two more days given for washing to remove formalin. The method applied for DNA isolation was Phenol Chloroform Extraction. In this method buffered tris-phenol used as a solvent to separate DNA from proteins and cell debris. ${ }^{6}$ Direct lyses method may cause DNA shearing and fails to 
remove the impurities. Therefore, extra purifications process was needed, which might yield less DNA. The samples were transferred to $1.5 \mathrm{ml}$ tubes and added $500 \mu 1$ Forensic buffer, $40 \mu 1$ SDS $20 \%, 25 \mu 1$ PK and 25 ditheothretol was added in each of the kept overnight at $56^{\circ} \mathrm{C}$ in thermo shaker for incubation. Next day, general method for organic extraction was used having Phenol, chloroform \& Iso-amyl alcohol. Sodium acetate and Iso propanol was used to precipitate the DNA and pellet was formed. DNA pellet was washed two times by $70 \%$ alcohol and last washing was done by $100 \%$ alcohol. Lastly, DNA was dissolved in $30 \mu 1 \mathrm{TE}^{7}$ The formalin preserved tissue were not able to generate sufficient quantity hence it were isolated by using automate extraction by using BTA kit as it is best way to isolate the DNA from the tissue material of foetus preserved in normal saline. ${ }^{8}$

DNA concentration of each sample was done by using Quantifiler $^{\circledR}$ Duo Quantification kit (Applied Bio systems) on instrument 7500 Real Time PCR machine as per the manufacturer's protocols. The real time PCR is able to distinguish and measure the DNA sequence in the samples. Moreover it also help to know the male DNA in the sample if there is missing $\mathrm{Y}$ allele on amelogenin and false representation of female to the male DNA can be ruled out. ${ }^{9}$ The sequences of DNA are amplified and monitor the amplification progress by fluorescent techniques. In this process amount of target sequence determined by the time how quick the fluorescent signal reaches the threshold level. The quantification of DNA assays combines three 5'nuclease assays including human specific DNA assay, human male DNA assay and an internal PCR control assays. Quantification Standards were used to determine the DNA quantity in each sample. The duo kit used, contains three different types of components, namely Taq Man ${ }^{\circledR}$ (which act as probe for human specific ribonuclease) RNA component H1 (RPPH1) gene), human male specific Sex-determining region Y (SRY) gene and an Internal Positive Control (IPC). ${ }^{2}$ The duo kit of applied Biosystem is best to exclude the misrepresentation of female in place of male due to deletion of Y allele in amelogenin.

\section{Amplification of DNA}

Effects of PCR inhibitors are known to us and therefore, effective measures were taken to avoid them. Autosomal STRs were amplified using AMPFlSTR ${ }^{\circledR}$ Identifiler Plus ${ }^{\circledR}$ TM PCR amplification kit (Applied Bio systems) according to the prescribed protocol. ${ }^{10}$ Amplified samples, now referred as amplicons, were loaded onto ABI 3500 XL genetic analyzer having Gene Mapper IDX 1.4 software for analysis. STR profiles that were been generated, were analyzed for all the samples. The degraded samples showing false peak profiles or allelic drop-out in big sized markers were further processed. The degraded tissues have shown alleles drop out samples were amplified using Minifiler kit, that targets the big sized markers and accordingly proper STR profiles were generated.

\section{Results and discussion}

In this study 15 different types of samples were taken including foetus in formalin, foetus limb in normal saline and toe in normal

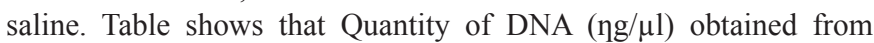
different samples on 7500 Real Time PCR machine and accordingly, percentage of success rate that is being observed from the data (Table 1). The result obtained from Real Time PCR shows only three sample preserved in formalin were able to give sufficient quantity for DNA profiling, even after all efforts made to remove the formalin from the tissue material. The limb of the foetus preserved in normal saline was able to generate sufficient DNA from the 14 samples except in one case and fourteen samples were able to generate full profile. The toe of the foetus was able to generate sufficient amount of DNA from all 15 samples resulting accurate and full DNA profiles from all samples (Figure 1).

Table I Real Time PCR machine and accordingly, percentage of success rate

\begin{tabular}{llll}
\hline S. No. & $\begin{array}{l}\text { Foetus in formalin } \\
\text { (DNA Qty. in ng) }\end{array}$ & $\begin{array}{l}\text { Foetus limb in normal } \\
\text { saline (DNA Qty. in ng) }\end{array}$ & $\begin{array}{l}\text { Foetus toe normal } \\
\text { saline (DNA Qty. In ng) }\end{array}$ \\
\hline I. & - & 1 & 2.04 \\
2. & - & 1.32 & 2.06 \\
3. & - & 1.09 & 1.35 \\
4. & 0.62 & - & 1.2 \\
5. & - & 0.42 & 0.55 \\
6. & - & 1.62 & 2.08 \\
7. & - & 0.98 & 1.32 \\
8. & - & 1.04 & 1.06 \\
9. & 0.7 & 0.7 & 0.98 \\
I0. & - & 1.29 & 2.32 \\
II. & - & 1.07 & 1.8 \\
I2. & 1.03 & 0.67 & 0.92 \\
I3. & - & 0.72 & 2.01 \\
I4. & - & 1.92 & 2.7 \\
I5. & - & 0.9 & 1.38 \\
Mean & 0.1567 & & \\
Value & & 0.984 & \\
\hline & & & \\
\hline
\end{tabular}




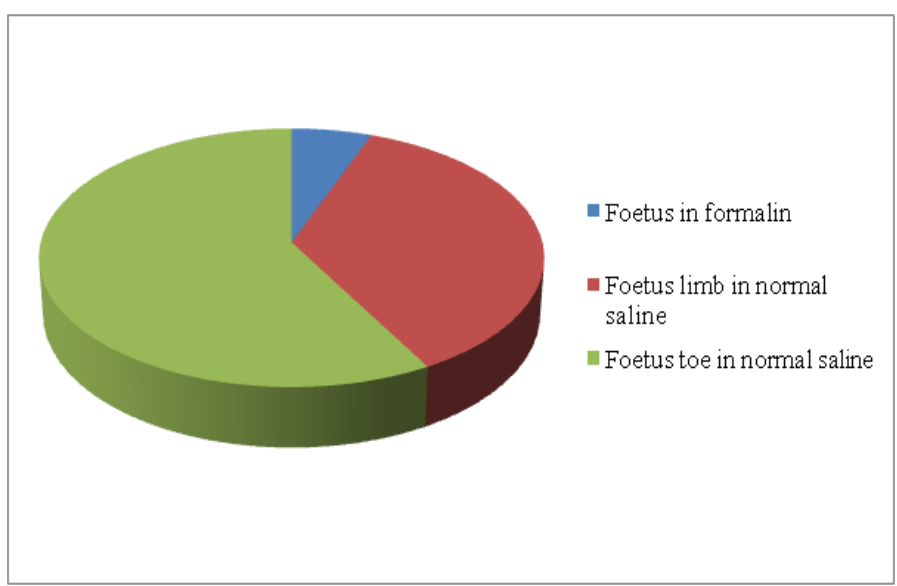

Pie-Chart showing the mean value of the above data
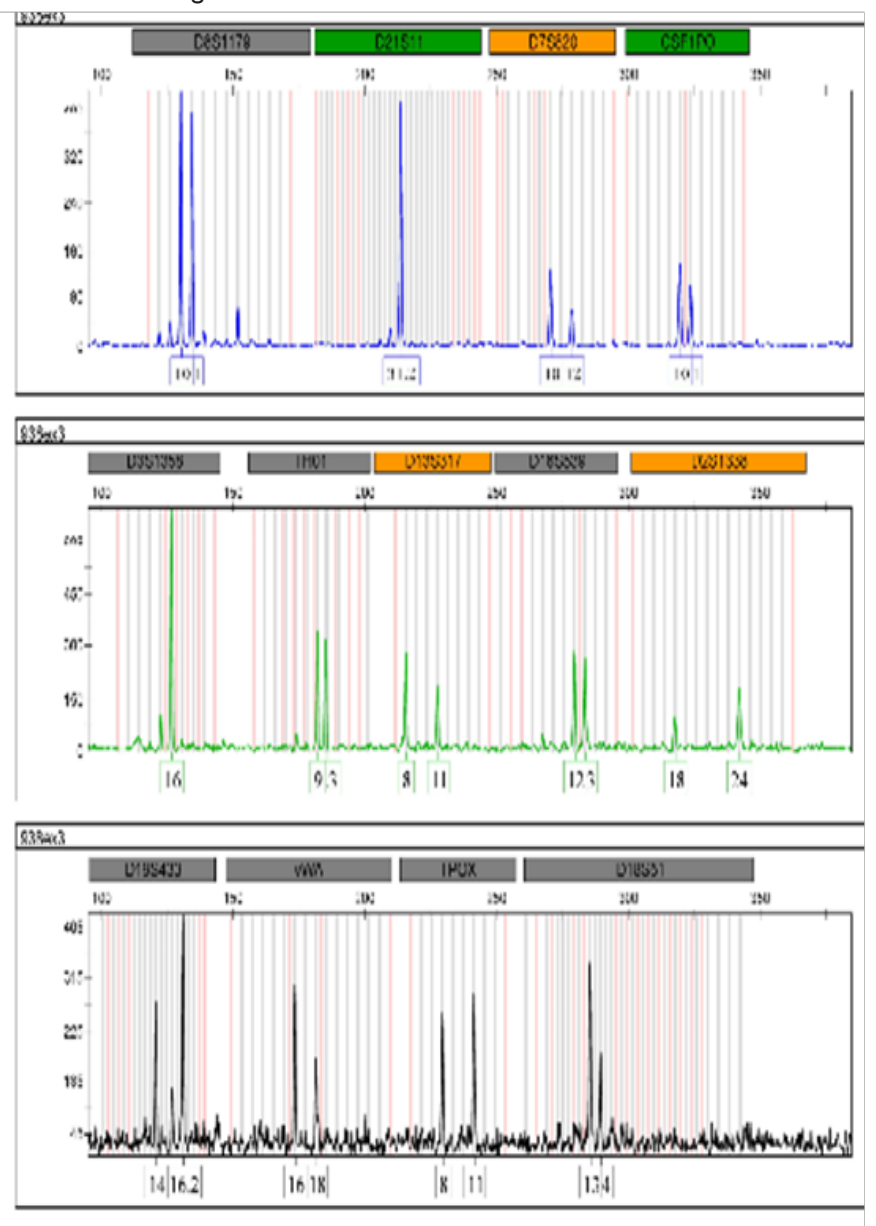

Figure I DNA profile prepared from the samples/tissue preserved in formalin.

\section{Conclusion}

From the above study it is clear that formalin is not the good preservative for the tissue materials. Success rate of DNA was poor from the samples preserved in formalin in forensic cases especially in foetus. Only three samples were able to generate accurate profiles. The toe samples preserved in normal saline is the best source for DNA profiling (Figure 2). The other tissue material of foetus preserved in normal saline is also good source for DNA profiling but less in quantity than toe in normal saline.
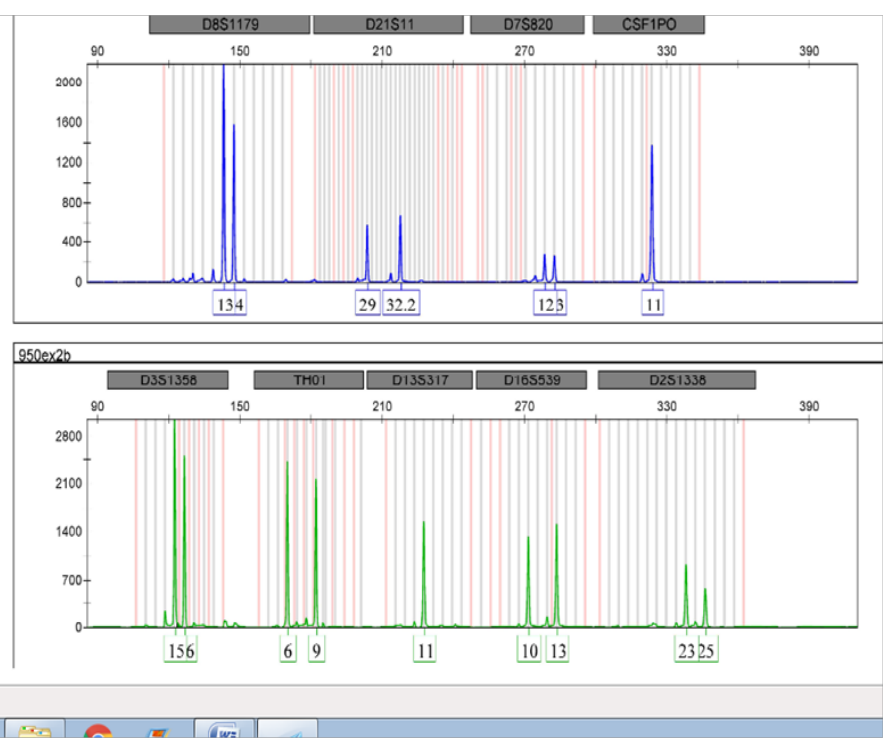

Figure 2 DNA profile prepared from the sample/tissue preserved in normal saline.

\section{Acknowledgements}

None.

\section{Conflict of interest}

None.

\section{References}

1. Moreira D. Efficient removal of PCR inhibitors using agarose-embedded DNA preparations. Nucleic Acids Research. 1998;26(13):3309-3310.

2. JM Butler. Forensic DNA typing. Biology, technology and genetics of STR markers. 2nd ed. New York: Elsvier Acedemic Press; 2005.

3. Del Rio SA, Marino MA, Belgrader P. PCR-based human leukocyte antigen (HLA) DQA1 typing of blood stained light and dark blue denim fabric. J Forensic Sci. 1996;41(3):490-492.

4. Thompson WC, Taroni F, Aitken CG. How the probability of a false positive affects the value of DNA evidence. $J$ Forensic Sci. 2003;48(1):47-54.

5. Inmana K, Rudin N. The origin of evidence. Forensic Science Int. 2002;126(1):11-16.

6. Ladd C, Bourke MT, Scherczinger CA, et al. A PCR-based strategy for ABO genotype determination. J Forensic Sci. 1996;41(1):134-137.

7. Wang WG, Kumar P, Schwarz M, et al. PCR amplification of 40-year paraffin-embedded tumour-tissues-comparison of 4 different DNA extraction and purification methods. Int J Oncol. 1994;5(3):453-457.

8. Kit PBFDE. Protocol. Thermmo Fisher Scientific.

9. Jha DK, Jiwan Pd Rijal, Nirajan T Chhetri. Nepalese Null AMELY males and their Y Haplotype. Scientific World. 2010;8(8):97-101.

10. Barrot C, Moreno C, Sanchez C, et al. Comparison of identifiler, identifiler plus and minifiler performance in an initial paternity testing study on old skeletal remains at the forensic and legal medicine area of the government of Andorra (Pyrenees). Forensic Science International: Genetics Supplement Series. 2011;3(1):15-16. 